\title{
Assessment of Maternal Readiness for Childbirth and Childrearing among Adolescent Mothers in Ghana
}

\author{
Rebecca Dordunu1, Gideon Dzando ${ }^{*}{ }^{(0)}$, Augustine Kumah ${ }^{3}$ (), Anthony B. Donyi ${ }^{4}$, \\ Hillary Selassi Nutakor5, Wonder A. Y. Amenuvor6, Charles Komla Anagblah7, \\ Eunice Adorkor ${ }^{8}$, Honore Mordenu' 9
}

${ }^{1}$ School of Nursing and Midwifery, University of Ghana, Legon, Ghana

${ }^{2}$ College of Nursing and Health Sciences, Flinders University, Adelaide, Australia

${ }^{3}$ Department of Quality and Public Health, Nyaho Medical Centre, Accra, Ghana

${ }^{4}$ Department of Nursing, Presbyterian University College, Agogo, Ghana

${ }^{5}$ Department of Mental Health, Accra Psychiatric Hospital, Accra, Ghana

${ }^{6}$ Department of Oncology, Ghana Health Service, Ho, Ghana

${ }^{7}$ Department of Nursing, Krachi West District Hospital, Krachi, Ghana

${ }^{8}$ Department of Nursing, Ho Teaching Hospital, Ho, Ghana

${ }^{9}$ School of Nursing and Midwifery, University of Cape Coast, Cape Coast, Ghana

Email: ^gdzando@gmail.com

How to cite this paper: Dordunu, R., Dzando, G., Kumah, A., Donyi, A.B., Nutakor, H.S., Amenuvor, W.A.Y., Anagblah, C.K., Adorkor, E. and Mordenu, H. (2021) Assessment of Maternal Readiness for Childbirth and Childrearing among Adolescent Mothers in Ghana. Advances in Reproductive Sciences, 9, 107-117.

https://doi.org/10.4236/arsci.2021.92011

Received: March 5, 2021

Accepted: April 22, 2021

Published: April 25, 2021

Copyright $\odot 2021$ by author(s) and Scientific Research Publishing Inc. This work is licensed under the Creative Commons Attribution International License (CC BY 4.0).

http://creativecommons.org/licenses/by/4.0/ (c) (i) Open Access

\begin{abstract}
Background: Adolescent pregnancy is a public health problem of concern in developed, developing and underdeveloped countries. Trends in developing and underdeveloped countries are higher and account for most adverse pregnancy outcomes. Adolescence is a period of transition between childhood and adulthood. The burden of coping with changes with this transition and at the same time preparing for childbirth puts pregnant adolescent girls on edge. Childbirth and childrearing are critical moments that require support and specialized skills to nurture healthy infants. Aim: This study aims to assess the readiness of adolescent expectant mothers towards childbirth and childrearing in the Komenda/Edina/Eguafo/Abirem (KEEA) district of the central region of Ghana. Methods: This study utilized the total population sampling technique to collect data from three sites that offer specialized adolescent antenatal services within the KEEA district of the central region of Ghana. Data were analyzed using SPSS version 22.0 and results presented as descriptive statistics. Results: This study assessed maternal readiness for childbirth and childrearing among 98 pregnant adolescent girls. The study was dominated by late adolescents who made up $86.7 \%$ of study participants. Regarding readiness for childrearing, the majority (74.5\%) said they could not independently cater
\end{abstract}


for their children and will require some support. The majority (52.0\%) have had some form of counseling with a greater number (41.2\%) coming from parents. Regarding readiness to embrace childbirth, the majority $(82.4 \%)$ of respondents said they had companions who were willing to support them during childbirth. The majority (57.1\%) of respondents have packed their delivery items although only $13.3 \%$ of them knew their expected dates of delivery. About $37.8 \%$ of respondents had knowledge of the possibility of having blood transfusion during delivery. Conclusion: Adolescent pregnancy is pervasive, and adolescent mothers require optimal support to ensure safe motherhood. Health promotion activities must be streamlined to meet their specific needs. Their significant others must actively be involved in their perinatal counseling to enhance compliance with health and wellbeing programs.

\section{Keywords}

Childbearing, Childrearing, Adolescence, Pregnancy, Antenatal Care

\section{Introduction}

The concept of childbearing and childrearing among adolescents has been identified as a public health problem that puts enormous stress on the young parents, the infant, and the broader community. Adolescent years are the continuance of human development and the transitional period from childhood to adulthood [1]. During this transition, individuals undergo a growth spurt with dramatic changes in their physical looks, emotional behavior, and their ways of interacting with other people. The World Health Organization identifies two stages of adolescence, namely early (10 - 14 years) and late (15 - 19 years) adolescence.

Pregnancy among adolescents is a global problem that affects people in developed, developing, and underdeveloped countries, with high prevalence in marginalized communities [2] [3]. Lack of education, unemployment, and poverty has been identified as major causes of pregnancy in adolescents. Approximately 21 million girls aged 15 - 19 years become pregnant each year in developing regions and 12 million of those pregnancies result in childbirth [4]. The United Nations Population Fund postulates that an estimated 777,000 adolescent girls below 15 years give birth in underdeveloped and developing regions annually [5].

Once an adolescent conceives and gives birth, there are inherent expectations for them to assume the direct responsibility of becoming the primary caregivers, as well as feeling a sense of fulfillment in their caregiver roles [6]. Society looks on and expects adolescent parents to bring up their children to fit into societal norms and live in socially acceptable ways. The ability to nurture and ensure an infant's physical, emotional, behavioural, and social development has often been regarded as a successful adaptation to the maternal role [7].

Adolescent mothers face health and social disadvantages including maternal 
complications during pregnancy and delivery, perinatal deaths, curtailed educational opportunities which often reduce their long-term social and economic status [8]. Childbearing and transitioning to parenthood often form the foundation and determines the long-term wellbeing of the child. As a social role, thus, assuming the responsibility often requires stringent planning and support from families and peers. In Sub-Saharan Africa, society frowns on adolescent pregnancies and this stereotyped belief has led to many adolescent mothers taking up their childrearing roles with little or no support [9]. Preparing and adjusting to changes during the perinatal period, therefore leaves these young mothers in perpetual stress which often translates to taking up unhealthy behaviours.

The indigenous notion about females not being prioritized in society, especially in Sub-Saharan Africa is gradually fading out. Women today occupy high offices in society, and it is expected that girl child education will be on the rise. Adolescent pregnancies have however threatened the realization of this progress, with an increase in reported cases of pregnancies among school-going girls [10].

Adolescent pregnancies form the majority of unintended pregnancies globally [11]. In Ghana, about $69.4 \%$ of unintended pregnancies occur among adolescents [12]. Childbearing and childrearing are special moments for adolescent mothers and require the best forms of preparation to take up their parenting roles and meet societal requirements of 'responsible motherhood'.

Although several studies have been conducted with regards to adolescent pregnancies, these studies have mainly focused on the causes and the overall impact of these pregnancies on adolescent mothers and the broader society. According to the 2010 population and housing census, the estimated population of the KEEA district is about 168,574 with males to female's ratio of 91.6:100 and an annual growth rate of $3.1 \%$. A UNFPA report of 2016 noted that the central region reported the highest number $(21.3 \%)$ of teenage pregnancies nationwide. A total of 497 teenage pregnancies were recorded in the KEEA district between January and September of that same year [13]. This present study seeks to assess the preparedness of adolescent mothers for childbirth and childrearing in the KEEA district of the central region of Ghana.

\section{Methods}

A descriptive cross-sectional study was conducted amongst 98 expectant adolescent mothers (10 - 19 years) who were attending specialized adolescent antenatal clinics (ANC) at the Kissi, Komenda and Elmina Health Centres in the KEEA district of the central region of Ghana (Kissi 29, Elmina 36, and Komenda 33). This study assessed maternal knowledge on care of pregnancy, and the associated health promotion activities associated with the perinatal period. The study also assessed the support services available to the pregnant adolescent girls including support from their families and the health services.

The KEEA District is one of the decentralized agencies in the Central Region of Ghana. It was formed in the year 1988 with Elmina as the district capital. The 
District is characteristic of a youthful population with a substantial segment of its population under the age of 15 years.

The study sites, Kissi, Komenda and Elmina were purposefully selected because they were the only health facilities in the district that offered specialized antenatal care to adolescents. The total registered pregnant adolescent girls in all three health centres were 112. All registered adolescents for the specialized ANC in the three facilities were included in the study. The total population sampling technique was used in selecting the respondents and a pretested closed ended structured questionnaire was used to collect data from the respondents. Data was collected over a period of three weeks, commencing with Kissi health centre in week one, Elmina in week two and Komenda in week three based on the schedule for specialized ANC for adolescents in these facilities. Data were cleaned and analysed using SPSS version 22.0. Results were presented as descriptive statistics.

\section{Results}

From Table 1, majority (86.7\%) of respondents were between ages 15 - 19 years of age. Whereas a meagre (5.1\%) of study participants have never been in school, the majority (94.9\%) have had some form of education at either primary, junior or senior high school levels. Concerning employment, $37.7 \%$ of study participants were unemployed, while the rest worked as traders (30.6\%), fishmongers

Table 1. Demographic Characteristics of respondents $(n=98)$.

\begin{tabular}{|c|c|c|}
\hline Demographic Characteristics & Frequency & Percentage \\
\hline \multicolumn{3}{|l|}{ Age in years. } \\
\hline Early adolescence: 10 - 14 & 13 & 13.3 \\
\hline Late adolescence: $15-19$ & 85 & 86.7 \\
\hline \multicolumn{3}{|l|}{ Educational status. } \\
\hline Never in school & 5 & 5.1 \\
\hline Primary & 26 & 26.5 \\
\hline JHS student/graduate & 62 & 63.3 \\
\hline SHS student/ graduate & 5 & 5.1 \\
\hline \multicolumn{3}{|l|}{ Occupation: } \\
\hline Trading & 30 & 30.6 \\
\hline Fishmongering & 19 & 19.4 \\
\hline Farming & 4 & 4.1 \\
\hline Sewing & 4 & 4.1 \\
\hline Hairdressing & 4 & 4.1 \\
\hline Not working & 37 & 37.7 \\
\hline \multicolumn{3}{|l|}{ Religion: } \\
\hline Christianity & 85 & 86.7 \\
\hline Islamic & 13 & 13.3 \\
\hline
\end{tabular}




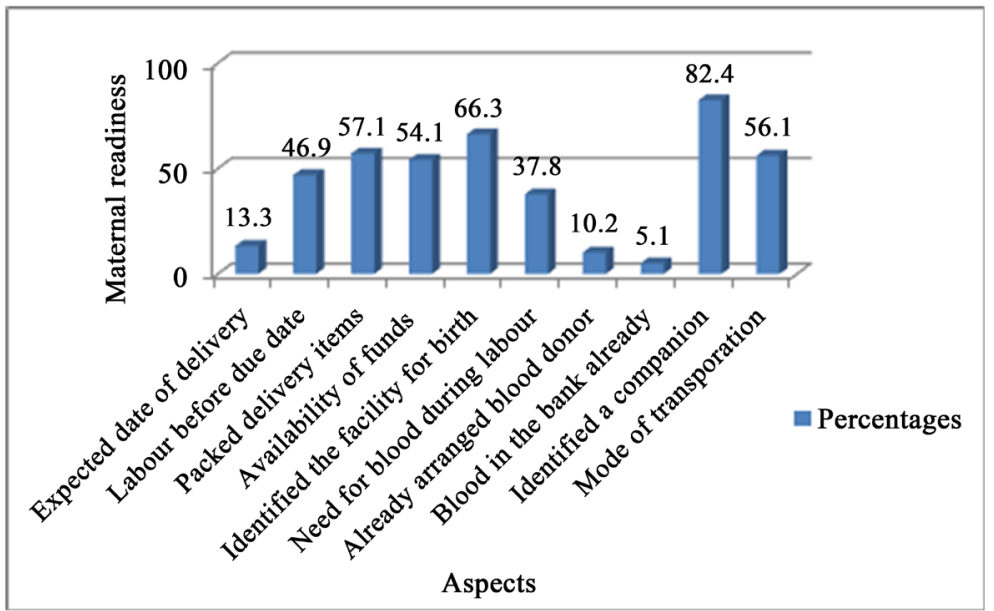

Figure 1. Aspects of maternal readiness for childbirth $(n=98)$ with multiple responses.

Table 2. Availability of support services for adolescent mothers.

\begin{tabular}{|c|c|c|}
\hline Response & Frequency & Percentage \\
\hline \multicolumn{3}{|c|}{ Someone to support mother and child financially after birth? $(n=98)$} \\
\hline Yes & 88 & 89.8 \\
\hline No & 10 & 10.2 \\
\hline \multicolumn{3}{|c|}{ If yes who? $(n=88)$} \\
\hline Partner & 21 & 23.9 \\
\hline Parents & 50 & 56.8 \\
\hline In-laws & 17 & 19.3 \\
\hline \multicolumn{3}{|c|}{ Able to care for child independently? $(n=98)$} \\
\hline Yes & 25 & 25.5 \\
\hline No & 73 & 74.5 \\
\hline \multicolumn{3}{|c|}{ If no, who will help you care for the child? $(n=73)$} \\
\hline Mother & 53 & 72.6 \\
\hline In-laws & 19 & 26.0 \\
\hline Siblings & 1 & 1.4 \\
\hline \multicolumn{3}{|c|}{ Caring for the baby is a difficult task and should be performed by experienced persons } \\
\hline Yes & 88 & 89.8 \\
\hline No & 10 & 10.2 \\
\hline \multicolumn{3}{|c|}{ Ever received counselling/education on child-rearing? $(n=98)$} \\
\hline Yes & 51 & 52.0 \\
\hline No & 47 & 48.0 \\
\hline \multicolumn{3}{|c|}{ Source of child-rearing education/counselling $(n=51)$} \\
\hline Parents & 21 & 41.2 \\
\hline In-laws & 8 & 15.7 \\
\hline Friends & 6 & 11.7 \\
\hline Nurses & 15 & 29.4 \\
\hline Doctors & 1 & 2.0 \\
\hline
\end{tabular}


Table 3. Maternal knowledge on infant nutrition.

\begin{tabular}{ccc}
\hline Variable & Frequency & Percentage \\
\hline Exclusive breastfeeding for the first 6 months & 65 & 35.5 \\
Complementary feeding at 6 months+ & 70 & 38.3 \\
Feeding child with food suggested at the CWC & 26 & 14.2 \\
Breastfeeding up to at least 2 years & 22 & 12.0 \\
Total & $\mathbf{1 8 3}^{*}$ & $\mathbf{1 0 0 . 0}$ \\
\hline
\end{tabular}

${ }^{\star}$ Multiple responses.

Table 4. Maternal knowledge on health promotion activities.

\begin{tabular}{ccc}
\hline Variable & Frequency & Percentage \\
\hline Attending Child Welfare Clinic regularly & 59 & 21.6 \\
Preventing child from home accidents & 54 & 19.9 \\
Responding promptly to child's basic needs & 44 & 16.2 \\
Comforting child whenever he or she cries & 49 & 18.0 \\
Protecting the child from extreme temperatures & 53 & 19.5 \\
Acquiring knowledge on first aid and home \\
management of children with diarrhea and fever
\end{tabular}

${ }^{*}$ Multiple responses.

(19.4\%), farmers, seamstresses and hairdressers each formed $4.1 \%$ each. Majority (86.7\%) of respondents were Christians while the rest (13.3\%) were of the Islamic faith.

Maternal readiness to embrace childbirth as depicted in Figure 1 indicates that majority $(82.4 \%)$ of respondents have companions willing to standby and support them during childbirth. Other variables identified through the preparedness process include knowledge of expected date of delivery (13.3\%), possibility of labour commencing before due date (46.9\%), Packed the necessary delivery items $(57.1 \%)$, availability of funds (54.1\%), identified the facility for delivery (66.3\%), possible need for blood during labour (37.8\%) and identified the mode of transportation to the health facility (56.1\%).

With regards to the availability of support services (Table 2), Majority (89.8\%) had support at their disposal, with parents providing the majority (56.8\%) of support. Other sources of support include partners (23.9\%) and inlaws (19.3\%). Majority (74.5\%) of study respondents said they could not independently cater for their children and will require support from their mothers (72.6\%), inlaws (26.0\%), and siblings (1.4\%). Majority (52.0\%) of respondents have received some form of counselling on child-rearing with a greater number (41.2\%) coming from parents. Other sources of counselling include inlaws (15.7\%), friends (11.7\%), nurses (29.4\%) and doctors (2.0\%). 
Concerning maternal knowledge on nutrition (Table 3), the multiple responses indicate that majority (38.3\%) of respondents had knowledge of complementary feeding. The adolescent mothers also had knowledge on exclusive breastfeeding (35.5\%), feeding children with suggested feeds from child welfare clinics (14.2\%) and breastfeeding for up to $2+$ years (12.0\%).

From Table 4, multiple responses regarding maternal knowledge on health promotion activities indicate that majority (21.6\%) had knowledge on the need to regularly attend antenatal clinics. Other activities identified were preventing home accidents (19.9\%), responding promptly to a child's basic needs (16.2\%), comforting the crying child (18.0\%), protecting the child from extremes of temperatures (19.5\%), and seeking knowledge on first aid for managing children at home $(4.8 \%)$.

\section{Discussion}

Adolescent pregnancies have remained an increasing source of concern in developing countries with social and economic consequences to both individuals and their communities. Majority of these pregnancies are unintended and tend to stem from environmental, sociocultural, individual, and health-related factors [10]. This study assessed the preparedness of pregnant adolescent girls towards caring for their pregnancies, coping with delivery, and caring for their infants after delivery. Late adolescent girls dominated the study, forming $86.7 \%$ of study participants. Adolescents at this age grow rapidly and are influenced by the things around them. They tend to assume more autonomy and explore so many behaviours around them. Findings from this study however contradict the results of a study conducted in Japan, where the annual rate of abortions and live births increased by $5.3 \%$ and $2.3 \%$ respectively among early adolescent girls [14]. Pregnant adolescent mothers require a good source of income for both their survival and the upkeep of their babies when they are born. However, unemployment in Ghana is a social problem, where graduates of tertiary institutions are unable to find jobs [15]. Results from this present study are consistent with findings from a similar study by [16] in which about $74 \%$ of sampled adolescent girls in Ghana were unemployed.

Preparing for childbirth is an important part of the perinatal period. Knowledge of an approximate date of delivery is important to ensure maximum preparation to safely welcome the new member of the family. From this present study, about $86.7 \%$ of the respondents did not know their expected date of delivery. This is in contrast with findings from a study by [17] in which about $89.2 \%$ of study respondents had knowledge of their expected dates of delivery. The disparity in findings could be a result of the difference in age groups of the respondents in both studies as the latter study involved pregnant women of all ages. The most planned aspect identified in this study was the availability of a companion to accompany the expectant mothers to the hospital (82.4\%), followed by identified facilities for childbirth (66.3\%). Mode of transportation, availability of 
funds and packed delivery items also had a preparedness level of $56.1 \%, 54.1 \%$ and $57.1 \%$ respectively. These findings are in support of a study conducted in Uganda by [18] where it was realized that birth preparedness aspects on four areas were high, including identification of health professional (61\%), saved money for delivery (91\%), identification of means of transport (61\%) and purchased delivery kits/birth materials during their most recent pregnancy (71\%).

Adolescent mothers require family and spousal support to realize positive pregnancy and childbirth outcomes. In this present study, the majority (89.8\%) of the pregnant adolescent girls attested to having financial support, of which more than half of the support is drawn from their parents. These findings contradict findings from a similar study conducted by [19], in which adolescent pregnant girls bemoaned how isolated they had become from their parents due to their pregnancies. Respondents from both studies however acknowledged and anticipated difficulty in caring for their newborns. Support for the adolescent expectant mothers in this present study was further noted in their sources of knowledge on child-rearing. Social and emotional support is important to ensure the wellbeing of the mother and baby postpartum [20]. Findings from this present study regarding the sources of support services indicate that partners play a lesser role in the lives of adolescent mothers. These findings mirror the assertion that majority of adolescent parents often become single parents [21].

The postpartum period is a period of transition for adolescent mothers to fully assume an additional responsibility of ensuring the wellbeing of the newborn in the family. The increasing competing demand at this stage can hamper the realization of health promotion behaviours [22]. Multiple responses from this present study revealed that adolescent mothers have inadequate knowledge of infant nutrition. This finding correlates with a study by [23] in which infant nutrition, especially breastfeeding was problematic for adolescent mothers. Complementary and supplementary feeding of infants is a costly venture [24]. Empowering adolescents by way of education is very important to prepare them towards making healthier choices after delivery. The antenatal services under the Ghana health service provide for educational and counselling sessions on infant nutrition which is aimed at educating expectant mothers on healthy choices in the perinatal period for both mothers and their infants. The inadequate knowledge levels thus can be due to the overall emotional, psychological, and social challenges associated with adolescent pregnancies. Also, the educational level of study participants can hinder their ability to retain information and may contribute to low levels of knowledge. This overall low level of knowledge is also evident in Table 4, where the multiple responses show less than half of the sampled adolescent girls had knowledge on each of the variables therein. Health promotion activities are important in ensuring safe motherhood. Growth monitoring activities, when commenced during the antenatal period promote maternal participation [25]. The difficulty in maintaining their own health and adopting healthy health promotion behaviours as adolescents translate into their roles as 
expectant mothers and for that matter mothers when their babies are born [26].

\section{Limitation}

This study utilized a descriptive cross-sectional approach where pre-tested closed-ended questionnaires were used to collect data from respondents. This limited the respondents' opportunity to explain in detail their responses regarding the variables under study. Secondly, pregnant women who were not registered for antenatal visits, or did not attend antenatal sessions on the specific days when data was collected were excluded from the study.

\section{Ethical Consideration}

Ethical approval for the study was obtained from The University of Cape Coast ethical review board and the Central regional health directorate. Participation in the study was solely by choice, and codes were used to identify respondents instead of names. Participants were encouraged to opt-out of the study at any point when they so wished.

\section{Conclusion}

Adolescent pregnancies are a threat to public health. Adolescent mothers tend to be disadvantaged and often go through emotional and psychological traumas to raise their children. Minimal support exists for these mothers, but often these supports come from the families of the adolescent girls. Their partners, if known, play dormant roles in supporting the welfare of the girls. Health education at antenatal services plays a significant role in preparing adolescent expectant mothers for childbirth and subsequent nurturing of their babies. Education on health promotion activities during antenatal visits ensures the overall wellbeing of the mothers and their infants, as well as helps in organizing support services to facilitate safe motherhood.

\section{Recommendation}

The researchers recommend further studies on social determinants that influence health-seeking behaviours in pregnant adolescent girls using an explorative qualitative approach.

The researchers also recommend that providing care for adolescent expectant mothers should involve their significant others. By so doing, information regarding health and wellbeing during the perinatal period will be well utilized. Policymakers should streamline perinatal health policies to meet specific adolescent needs to help them bridge the gap between meeting their own demands as adolescents and preparing to nurture their newborns.

\section{Conflicts of Interest}

The authors declare no conflicts of interest regarding the publication of this paper. 


\section{References}

[1] Steinberg, L. (2014) Age of Opportunity: Lessons from the New Science of Adolescence. Houghton Mifflin Harcourt, USA.

[2] UNICEF (2013) Ending Child Marriage: Progress and Prospects. UNICEF, New York.

[3] Sedgh, G., Finer, L.B., Bankole, A., Eilers, M.A. and Singh, S. (2015) Adolescent Pregnancy, Birth, and Abortion Rates across Countries: Levels and Recent Trends. Journal of Adolescent Health, 56, 223-230. https://doi.org/10.1016/j.jadohealth.2014.09.007

[4] Darroch, J.E., Woog, V., Bankole, A., Ashford, L.S. and Points, K. (2016) Costs and Benefits of Meeting the Contraceptive Needs of Adolescents. Guttmacher Institute.

[5] UNFPA (2015) Girlhood, Not Motherhood: Preventing Adolescent Pregnancy. UNFPA, New York.

[6] Ruedinger, E. and Cox, J.E. (2012) Adolescent Childbearing: Consequences and Interventions. Current Opinion in Pediatrics, 24, 446-452. https://doi.org/10.1097/MOP.0b013e3283557b89

[7] Shrestha, S., Adachi, K.A., Petrini, M. and Shrestha, S. (2019) Maternal Role: A Concept Analysis. Journal of Midwifery and Reproductive Health, 7, 1732-1741.

[8] Marphatia, A.A., Ambale, G.S. and Reid, A.M. (2017) Women's Marriage Age Matters for Public Health: A Review of the Broader Health and Social Implications in South Asia. Frontiers in Public Health, 5, Article 269. https://doi.org/10.3389/fpubh.2017.00269

[9] Hall, K.S., Manu, A., Morhe, E., Dalton, V.K., Challa, S., Loll, D. and Harris, L.H. (2018) Bad Girl and Unmet Family Planning Need among Sub-Saharan African Adolescents: The Role of Sexual and Reproductive Health Stigma. Qualitative Research in Medicine \& Healthcare, 2, 55-64. https://doi.org/10.4081/qrmh.2018.7062

[10] Yakubu, I. and Salisu, W.J. (2018) Determinants of Adolescent Pregnancy in Sub-Saharan Africa: A Systematic Review. Reproductive Health, 15, Article No. 15. https://doi.org/10.1186/s12978-018-0460-4

[11] Sedgh, G., Singh, S. and Hussain, R. (2014) Intended and Unintended Pregnancies Worldwide in 2012 and Recent Trends. Studies in Family Planning, 45, 301-314. https://doi.org/10.1111/j.1728-4465.2014.00393.x

[12] Ameyaw, E.K. (2018) Prevalence and Correlates of Unintended Pregnancy in Ghana: Analysis of 2014 Ghana Demographic and Health Survey. Maternal Health, Neonatology and Perinatology, 4, Article No. 17. https://doi.org/10.1186/s40748-018-0085-1

[13] KEEA Health Directorate (2016) Annual Health Report. KEEA Health Directorate, Elmina.

[14] Baba, S., Goto, A. and Reich, M.R. (2014) Recent Pregnancy Trends among Early Adolescent Girls in Japan. Journal of Obstetrics and Gynaecology Research, 40, 125-132. https://doi.org/10.1111/jog.12138

[15] Anarfi, K., Hill, R.A. and Shiel, C. (2020) Highlighting the Sustainability Implications of Urbanisation: A Comparative Analysis of Two Urban Areas in Ghana. Land, 9, 300. https://doi.org/10.3390/land9090300

[16] Hall, K.S., Morhe, E., Manu, A., Harris, L.H., Ela, E., Loll, D. and Dalton, V.K. (2018) Factors Associated with Sexual and Reproductive Health Stigma among Adolescent Girls in Ghana. PLoS ONE, 13, e0195163.

https://doi.org/10.1371/journal.pone.0195163 
[17] Agbodohu, D. (2013) Birth Preparedness and Complication Readiness Among Expectant Mothers at the Ridge Regional Hospital, Accra. Doctoral Dissertation, University of Ghana, Ghana.

[18] Kabakyenga, J.K., Ostergren, P.O., Turyakira, E. and Pettersson, K.O. (2011) Knowledge of Obstetric Danger Signs and Birth Preparedness Practices among Women in Rural Uganda. Reproductive Health, 8, Article No. 33.

https://doi.org/10.1186/1742-4755-8-33

[19] James, S., Van Rooyen, D. and Strümpher, J. (2012) Experiences of Teenage Pregnancy among Xhosa Families. Midwifery, 28, 190-197. https://doi.org/10.1016/j.midw.2011.04.003

[20] Negron, R., Martin, A., Almog, M., Balbierz, A. and Howell, E.A. (2013) Social Support during the Postpartum Period: Mothers' Views on Needs, Expectations, and Mobilization of Support. Maternal and Child Health Journal, 17, 616-623.

https://doi.org/10.1007/s10995-012-1037-4

[21] WHO (2014) Adolescent Pregnancy. http://www.who.int/mediacentre/factsheets/fs364/en/.

[22] Trotman, G., Chhatre, G., Darolia, R., Tefera, E., Damle, L. and Gomez-Lobo, V. (2015) The Effect of Centering Pregnancy Versus Traditional Prenatal Care Models on Improved Adolescent Health Behaviors in the Perinatal Period. Journal of Pediatric and Adolescent Gynecology, 28, 395-401. https://doi.org/10.1016/j.jpag.2014.12.003

[23] Erfina, E., Widyawati, W., McKenna, L., Reisenhofer, S. and Ismail, D. (2019) Exploring Indonesian Adolescent Women's Healthcare Needs as They Transition to Motherhood: A Qualitative Study. Women and Birth, 32, e544-e551. https://doi.org/10.1016/j.wombi.2019.02.007

[24] Dipasquale, V., Serra, G., Corsello, G. and Romano, C. (2020) Standard and Specialized Infant Formulas in Europe: Making, Marketing, and Health Outcomes. Nutrition in Clinical Practice, 35, 273-281. https://doi.org/10.1002/ncp.10261

[25] Kohli, S. and Chadha, R. (2017) Knowledge and Counselling Skills of Community Health Workers for Promotion of Optimal Infant and Young Child Feeding (IYCF) Practices: A Review. International Journal of Health Sciences and Research, 7, 240-251.

[26] Salam, R.A., Faqqah, A., Sajjad, N., Lassi, Z.S., Das, J.K., Kaufman, M. and Bhutta, Z.A. (2016) Improving Adolescent Sexual and Reproductive Health: A Systematic Review of Potential Interventions. Journal of Adolescent Health, 59, S11-S28. https://doi.org/10.1016/j.jadohealth.2016.05.022 